Fayetteville State University

DigitalCommons@Fayetteville State University

6-1-2011

\title{
Vestigial structures in the appendicular skeletons of eight African skink species (Squamata, Scincidae)
}

J. G. Moch

Philip J. Senter

Fayetteville State University, psenter@uncfsu.edu

Follow this and additional works at: https://digitalcommons.uncfsu.edu/bio_wp

\section{Recommended Citation}

Moch, J. G. and Senter, Philip J., "Vestigial structures in the appendicular skeletons of eight African skink species (Squamata, Scincidae)" (2011). Biological Science Faculty Working Papers. 4.

https://digitalcommons.uncfsu.edu/bio_wp/4

This Article is brought to you for free and open access by the Biological Science at DigitalCommons@Fayetteville State University. It has been accepted for inclusion in Biological Science Faculty Working Papers by an authorized administrator of DigitalCommons@Fayetteville State University. For more information, please contact dballar5@uncfsu.edu. 


\title{
Vestigial structures in the appendicular skeletons of eight African skink species (Squamata, Scincidae)
}

\author{
J. G. Moch \& P. Senter \\ Department of Natural Sciences, Fayetteville State University, Fayetteville, NC, USA
}

\begin{abstract}
Keywords
vestigial structures; vestigial organs; limb reduction; Squamata; Scincidae; Acontias; Typhlosaurus; Typhlacontias; Sepsina; Scelotes; Lerista.

Correspondence

Phil Senter, Department of Biological Sciences, Fayetteville State University, 1200 Murchison Road, Fayetteville, NC 28301, USA.

Email: jgmoch01@broncos.uncfsu.edu, psenter@uncfsu.edu
\end{abstract}

Editor: Andrew Kitchener

Received 28 March 2011; revised 1 June 2011; accepted 6 June 2011

doi:10.1111/j.1469-7998.2011.00839.x

\begin{abstract}
Limb reduction and loss, with reduction of limb and girdle skeletons to a vestigial state, has occurred several times independently within the skink family (Scincidae). The vestigial appendicular skeletons of most limbless skinks have not been described before now. Here we describe those of eight African skink species, all with a burrowing lifestyle: Acontias percivali, Acontias meleagris, Typhlosaurus cregoi, Typhlosaurus lineatus, Typhlacontias gracilis, Sepsina bayonii, Scelotes anguina and Scelotes arenicola. For all but two (A. meleagris and Sc. arenicola) the appendicular skeletons were previously undescribed. Limbs are absent in all specimens except for vestigial hindlimbs in Se. bayonii and vestigial femurs in one specimen of Sc. arenicola. In our sample, the pectoral girdle is reduced to a pair of tiny slivers in A. percivali, Ty. gracilis, Se. bayonii and Sc. anguina. It is absent in the other specimens. The pelvic girdle is absent in Ty. cregoi. In all the rest but Se. bayonii it is vestigial, retaining only the ilium in A. meleagris, Ty. lineatus and one specimen of Sc. arenicola. This study adds to the number of skink species with vestigial appendicular skeletons that have been described. It also adds to the range of documented intraspecific variation in the vestigial appendicular skeletons of $A$. meleagris, Sc. arenicola and the Australian skinks Lerista stylis and Lerista carpentariae. We observed asymmetry between the left and right sides in the vestigial appendicular skeletons of four of the African skink species: A. meleagris, Sc. anguina, Sc. arenicola and Se. bayonii.
\end{abstract}

\section{Introduction}

A vestigial structure is a rudimentary biological structure that is evolutionarily derived from a larger, more fully functional homolog. Darwin (1871) recognized the existence of vestigial structures as an important line of evidence for biological evolution (heritable change through generations) in general and macroevolution (evolution at large taxonomic scales) in particular. This recognition continues among biologists today (e.g. Starr \& Taggart, 2004; Campbell et al., 2009).

Vestigial limb and girdle skeletons are known in several lineages of squamate reptiles in which limbs are reduced or lost. Examples include the squamate taxa Serpentes (snakes) (Essex, 1927; Bellairs, 1950; Mlynarski \& Madej, 1961; List, 1966), Amphisbaenia (amphisbaenians) (Kearney, 2002), Dibamidae (Greer, 1991), Pygopodidae (Fürbringer, 1870; Stephenson, 1961), Cordylidae (Essex, 1927), Anguidae (Fürbringer, 1870; Stokely, 1947), Anniellidae (Cope, 1892; Stokely, 1947) and Adriosaurus (Palci \& Caldwell, 2007). Limb reduction and loss has also occurred multiple times within Scincidae, the family of lizards known as skinks. Partial or complete limb loss is present in a plethora of skink species, including members of at least 20 genera. However, to our knowledge, vestigial elements of the appendicular skeleton in Scincidae have been described in members of only five skink genera: Typhlosaurus (Fürbringer, 1870), Acontias (Fürbringer, 1870; Essex, 1927; Stokely, 1947), Feylinia (Cope, 1892; Essex, 1927), Scelotes (Essex, 1927; Renous \& Gasc, 1979) and Chalcides (Steiner \& Anders, 1946; Stokely, 1947). In studies on limb reduction and loss in skinks, that were published after the wave of skeletal descriptions of the late 1800 s and early 1900s, the emphasis has typically been on function (e.g. Wiens, Brandley \& Reeder, 2006), phylogenetic patterns (e.g. Greer, 1991; Whiting, Bauer \& Sites, 2003; Skinner, Lee \& Hutchinson, 2008) or developmental processes (e.g. Shapiro et al., 2003; Young et al., 2009), rather than on skeletal description. Here we seek to partially fill this gap in published knowledge by documenting vestigial parts of the appendicular skeletons of eight species of skink in five genera.

In a previous publication one of us introduced a phylogenetic bracketing approach to determine whether or not a reduced skeletal structure should be considered vestigial (Senter, 2010). According to this approach a structure is considered vestigial if it satisfies two criteria in comparison to the condition of its homolog in at least three successive sister groups. First, the structure is reduced to one-third or 
less its size relative to adjacent skeletal structures, in comparison to its relative size in the sister groups. The choice of one-third as the cutoff for recognition of extreme reduction is somewhat arbitrary and does not have to be followed in every study. However, it does ensure that the size reduction of the structure in question is pronounced, which is necessary in order to demonstrate that extreme reduction has occurred, and it is therefore followed in the present study. The second criterion used in the previous study (Senter, 2010) is that, at least distally, the structure has lost the specialized morphology that it exhibits in the three successive sister groups. This criterion is also used in the present study. The choice of three as the minimum number of sister groups for comparison is not arbitrary. The use of a phylogenetic bracketing approach to infer an ancestral state requires confirmation of the state in a minimum of two successive sister groups (e.g. Witmer, 1995), and the confirmation of the state in a third sister group makes the inference more robust.

To the two criteria listed above for recognition of a skeletal structure as vestigial we now add a third, functional criterion: uselessness of the structure in question with respect to its ancestral function (its function in its unreduced form in at least three successive sister groups). For example, a lizard limb satisfies this criterion if it is too miniscule to serve as an organ of propulsion, and it is an organ of propulsion in at least three successive sister groups. Likewise, the pectoral or pelvic girdle of a lizard satisfies this criterion if it is too reduced to support a full limb and the muscles that operate it for propulsion, and in at least three successive sister groups it supports a full limb and the muscles that operate it for propulsion. A lizard pelvic girdle further satisfies this criterion if it is not connected to the vertebral column, because such a connection facilitates propulsion with the hindlimb by bracing each hindlimb against the other, which is the norm for terrestrial tetrapods (Kardong, 2006). As has previously been pointed out (Isaak, 2007), a structure does not have to be completely useless to be considered vestigial. For example, the vestigial second and fourth metacarpals and metatarsals of horses function as guides for suspensory ligaments (Smythe, 1967) but are useless for their ancestral function as finger and toe supports. Note that this criterion only applies to structures with an obvious and/or known function, for example, a wing or a limb. It is not necessarily applicable to functionally mysterious structures such as an osteoderm or a cranial knob. For such structures vestigiality can be assessed without reference to function, by considering only the two criteria from the previous paragraph.

The skink genera examined for this study are members of the African genera Acontias, Typhlosaurus, Typhlacontias, Sepsina and Scelotes, all of which are burrowers (Branch, 1998). The degree of limb reduction varies among and within these genera. External limbs are absent in Acontias and Typhlosaurus. Typhlacontias includes one species, Typhlacontias brevipes, with tiny external hindlimbs, and others with no external limbs. Members of Sepsina have reduced limbs with missing digits that are nonetheless functional in some species. Scelotes includes some species with fully functional, pentadactyl limbs, some with reduced limbs, and others that lack external limbs (Branch, 1998). For each of these genera there are at least three successive sister groups with fully propulsive, pentadactyl limbs (Fig. 1).

Appendicular skeletons have been described for two of the skink species included in this study: Acontias meleagris (Fürbringer, 1870) and Scelotes arenicola (Renous \& Gasc, 1979). We kept these in the study to document potential intraspecific variation. To our knowledge, appendicular skeletons have not been described for any species of Typhlacontias or Sepsina, nor for the species of Acontias, Typhlosaurus and Scleotes that are included in this study, with the exception of the two species mentioned above.

\section{Materials and methods}

J. G. M. used a digital micro X-ray machine to produce Xrays of preserved specimens in the herpetological collection facility of the United States National Museum. Taxa to be X-rayed were chosen based on availability of preserved specimens at the facility, large enough body sizes to accommodate the limited resolution capability of the X-ray machine, and the desire to include the largest possible taxonomic sample within the limited time that was available to J. G. M. As a result, for several species only one specimen was X-rayed. Specimen accession numbers are given in the figure captions.

Two Australian skink species, Tiliqua scincoides and Lerista orientalis, were X-rayed to illustrate the appearance of non-vestigial skink limb and girdle skeletons in X-ray

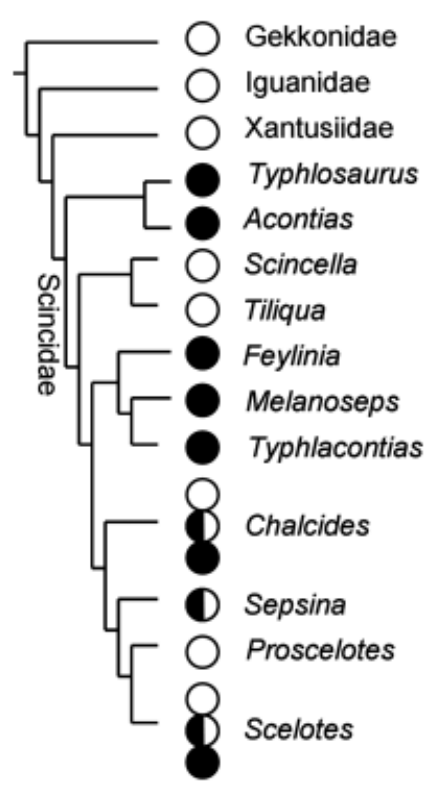

Figure 1 Phylogenetic relationships of the African skink genera examined in this paper (Whiting et al., 2003; Wiens et al., 2006), showing that for each genus there are at least three sister groups with full, pentadactyl limbs. White circles, full, pentadactyl limbs; black circles, no external limbs; half-filled circles, vestigial external limbs. 


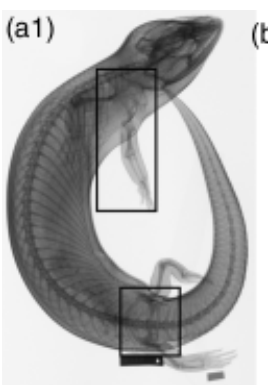

(a2)

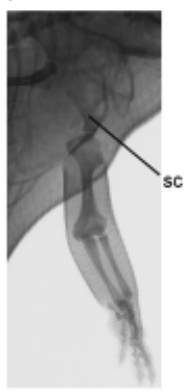

(a3)
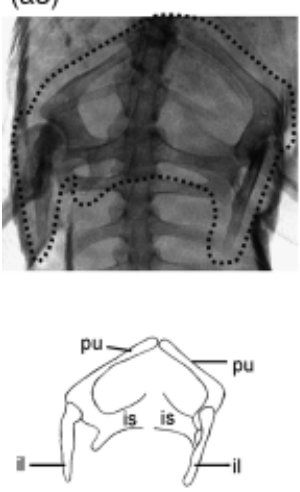

(b1)

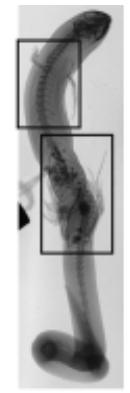

(b2)

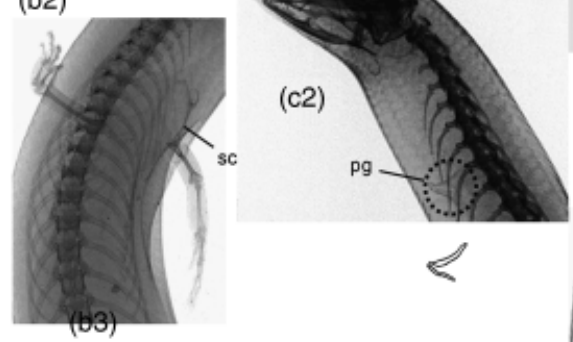

(b3)

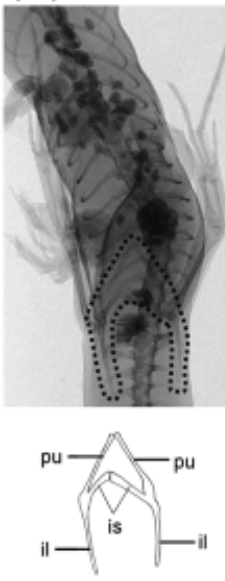

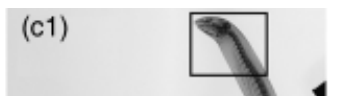

(d1)
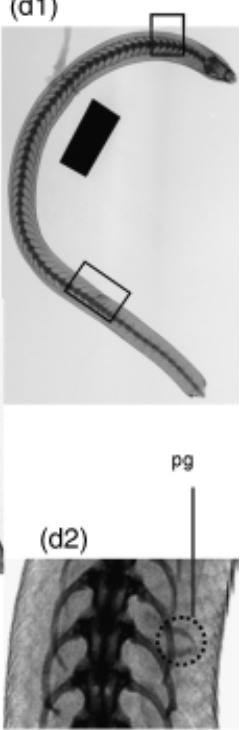

(c3)

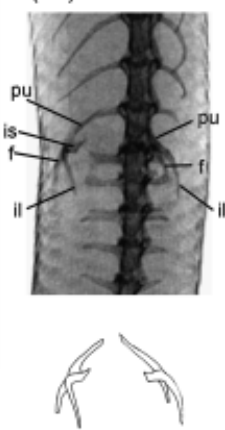

(d3)

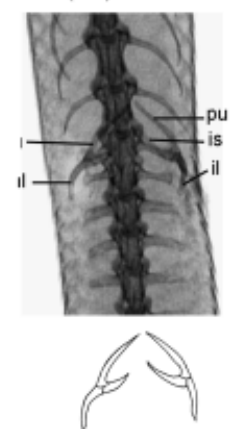

Figure 2 X-rays of Australian skinks, showing various states of limb and girdle reduction. In all cases images 2 and 3 are enlargements of the areas indicated by boxes in image 1, and the line drawing for image 3 is of the limb and/or girdle shown in the associated X-ray image. In each case the dark, rectangular shape with the hole in one end is the metal specimen tag, and the solid rectangular shape is a $20 \mathrm{~mm}$ scale bar. (a) Tiliqua scincoides, USNM 62720, showing full, unreduced girdles and limbs. (b) Lerista orientalis, USNM 128408, showing unreduced girdles and limbs that have lost one digit apiece. (c) Lerista stylis, USNM 128658, showing vestigial girdles, loss of forelimbs, and hindlimbs represented only by the femur. (d) Lerista carpentariae, USNM 128409, showing vestigial girdles and complete limb loss. f, femur; il, ilium; is, ischium; pg, pectoral girdle bones; pu, pubis; sc, scapula.

One specimen of Ti. scincoides was examined (Fig. 2a). All four limbs are present, each with five unreduced digits. The pubes are rodlike and meet in the midline at approximately three VLA. The ischia are flat plates, each with a blunt prong on the caudal end, that meet in the midline between the two acetabula.

One specimen of L. orientalis was examined (Fig. 2b). All four limbs are present, each with four unreduced digits, and none is vestigial, although the forelimbs are only $55 \%$ the length of the hindlimbs. The pubes are simple rods that meet in the midline at c. 3.5 VLA. The ischia are simple rods that meet in the midline between two and three VLA. The ilia extend posteriorly approximately five VLA and are attached to a pair of sacral vertebrae.

One specimen of L. stylis was examined (Fig. 2c). Forelimbs are absent and a rudimentary pectoral girdle is present as a pair of short slivers with slightly less than the diameter of a rib. The pelvic girdle is present on both sides, with each of its bones reduced to a sliver with approximately the 

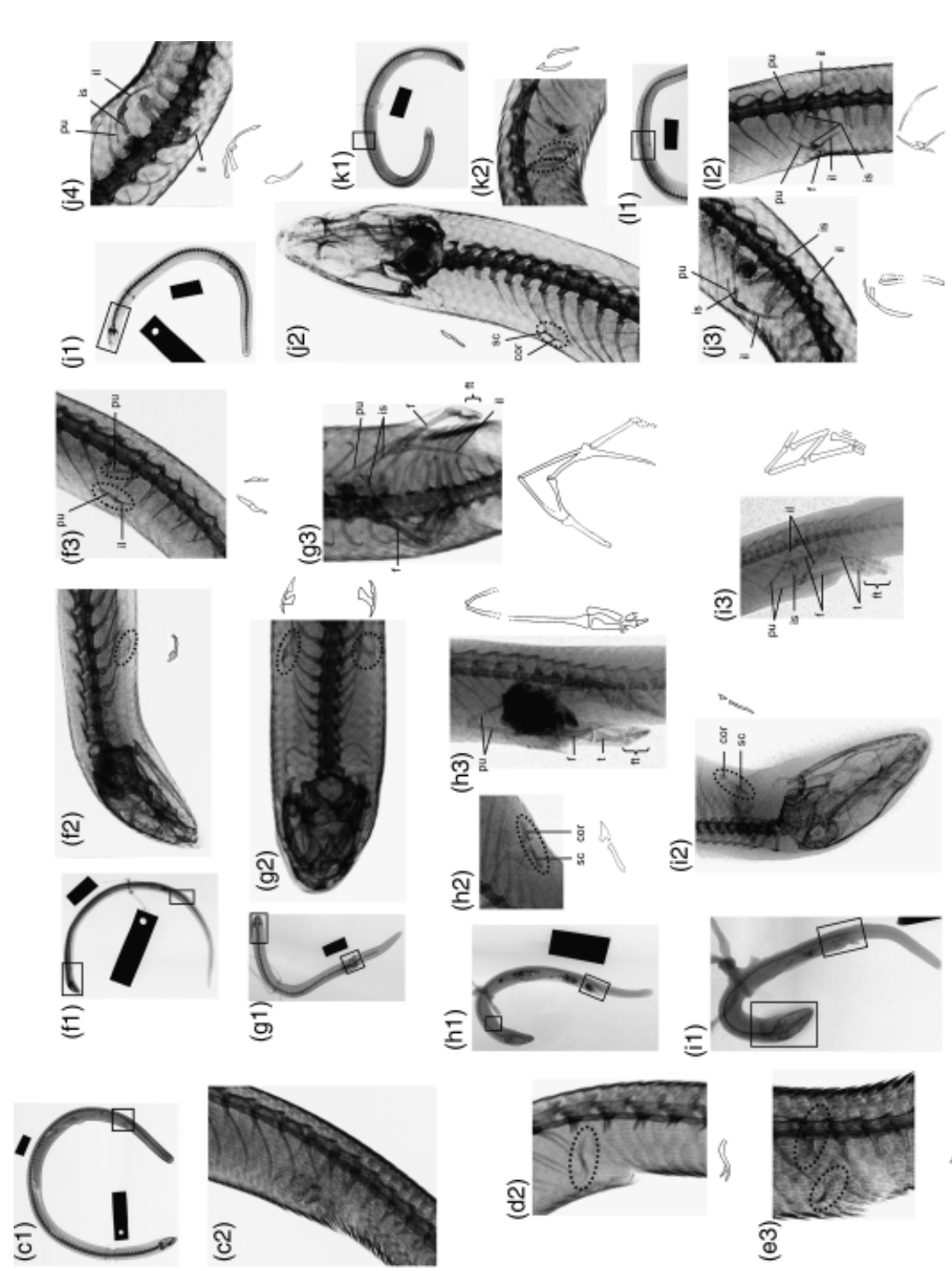

ब)

응

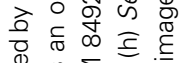

幽.

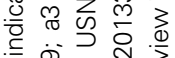

क्षे

\%

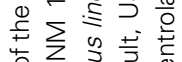

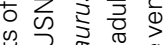

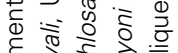

ब

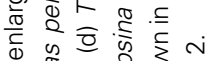

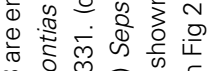

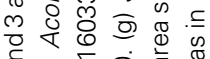

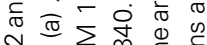

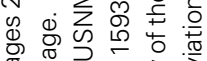

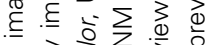

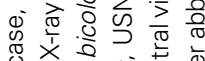

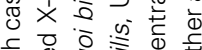

다워

(ब)

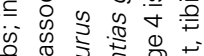

है

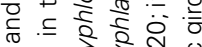

व से

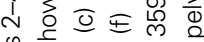

बू山

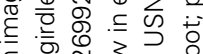

닌

至

है है क्षे

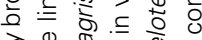

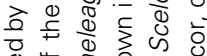

ه 4 ह ह

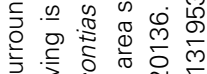

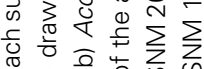

ब
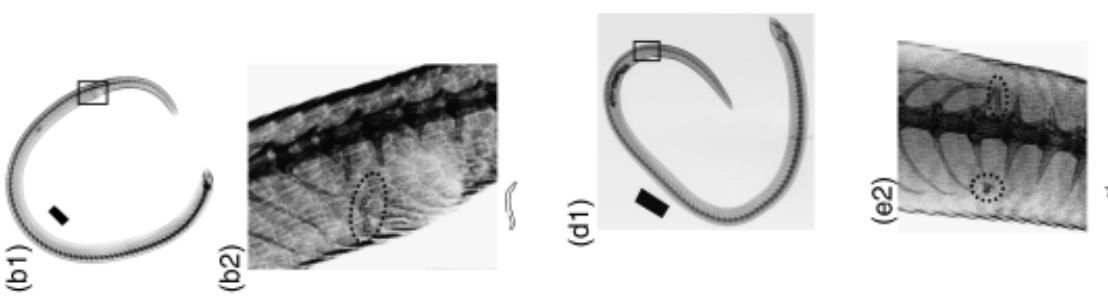

ब)

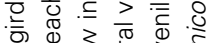

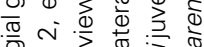

吾

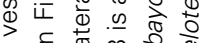

D.

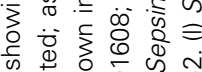
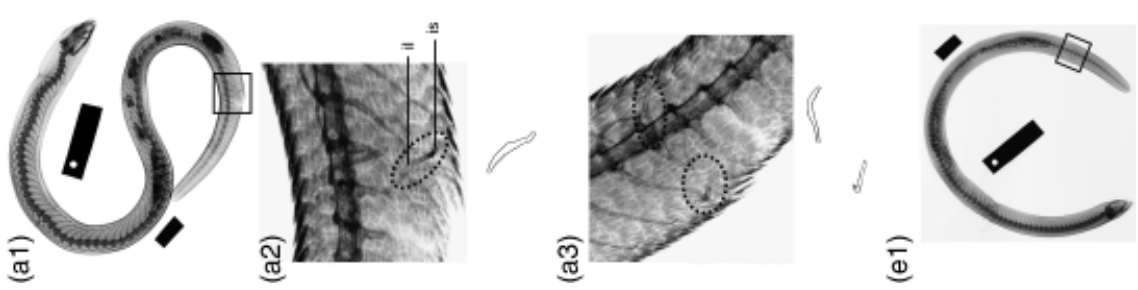

i)

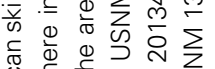

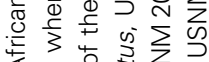

安等

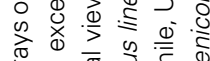

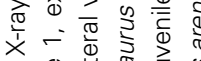

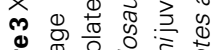

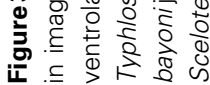


diameter of a rib. Pubes and ischia both extend craniomedially from their point of articulation with the ilium. The left and right pubes meet in the midline at $c .1 .5 \mathrm{VLA}$, and the ischia stop just short of meeting in the midline at approximately one VLA. The ilia are broadly curved, extend caudally a little more than one VLA and are not connected with the vertebral column. A small femur, a tiny sliver approximately the diameter of a rib and approximately the length of one vertebra, is present on each side in articulation with the acetabulum.

One specimen of L. carpentariae was examined (Fig. 2d). Limbs are absent. The girdles resemble their counterparts in L. stylis but the pubes are shorter, extending forward only one VLA. The pectoral girdle is present on the right side only.

One specimen of Acontias percivali was examined (Fig. 3a). Limbs and a bony pectoral girdle are absent. Rudimentary left and right pelvic girdles are present, each a thin sliver approximately the diameter of a rib. In each pelvic girdle is a vertical ilium with a caudally bent dorsal end and a transversely oriented ischium that is only about one-third the length of the ilium. The pelvic girdles are not connected to the vertebral column.

One specimen of $A$. meleagris was examined (Fig. 3b). Limbs and a bony pectoral girdle are absent. The pelvic girdle is present only on the left side and consists only of a rudimentary ilium. The ilium is a vertical sliver with approximately the diameter of a rib and with its dorsal end bent caudally. It is not connected to the vertebral column. In a previously figured specimen of this species, the pectoral and pelvic girdles of both sides are present; each is a miniscule rod (Fürbringer, 1870).

One specimen of Typhlosaurus cregoi bicolor was examined (Fig. 3c). Limbs are absent and there is no bony pectoral or pelvic girdle.

Two specimens of Typhlosaurus lineatus were examined (Fig. 3d and e). Limbs are absent and there is no bony pectoral girdle. In both specimens the pelvic girdle is present on both sides and consists mainly or entirely of a vertical ilium, less than the length of one vertebra, with its dorsal end bent caudally. The ventral end of each girdle may be a miniscule ischium, but it is difficult to be certain that more than the ilium is present. The pelvic girdles are not connected to the vertebral column.

One specimen of Typhlacontias gracilis was examined (Fig. 3f). Limbs are absent. A rudimentary pectoral girdle is present. It appears to consist of two joined bones, each a little less than the length of one vertebra. The pelvic girdle is present on both sides. The ilia lean caudally, extending caudally for less than one VLA. In each pelvic girdle the pubis extends craniomedially from the ilium and is slightly less than the length of one vertebra. The pelvic girdles are not connected to the vertebral column.

Three specimens of Sepsina bayonii were examined: one adult (Fig. 3g) and two juveniles (Fig. 3h and i). Forelimbs are absent. Rudimentary scapulae and coracoids, each a small sliver, are present, separated by a small gap. They are relatively smaller in the adult than in the juveniles. Vestigial hindlimbs are present, with a femur approximately the length of five vertebrae in the adult, four in one juvenile and three and a half in the other juvenile. The tibia is approximately the length of one vertebra in the adult and two in the juveniles. In all three specimens a few tarsals, metatarsals and phalanges are present as tiny nubs, too small to count. The pubes and ischia extend craniomedially and meet in the midline in the adult. In one juvenile, the ischia are obscured from view by gut contents. In the other, they extend transversely to meet in the midline. A small gap separates the ilia from the transverse processes of a pair of vertebrae that have typical sacral morphology. Connecting cartilage may have filled this gap, but this cannot be verified in the X-ray image. In the adult the left and right girdles, despite meeting in the ventral midline, are placed asymmetrically; the right pelvic girdle is more cranial than the left so that its acetabulum is $c .1 .5 \mathrm{VL}$ cranial to the left acetabulum.

One specimen of Sc. anguina was examined (Fig. 3j). Limbs are absent. A miniscule scapula and coracoid are present only on the right side, each less than the length of one vertebra and with a smaller diameter than a rib. The pelvic girdle is present on both sides, and each bone is a sliver approximately the diameter of a rib. The right pelvic girdle is shifted anteriorly by approximately the length of one vertebra. The pubes and ischia extend craniomedially and are too short to reach the midline. The pubes extend forward approximately one VLA, and the ischia extend forward $c$. 0.5 VLA. The ilia extend posteriorly approximately three VLA and are not connected to the vertebral column.

Two specimens of $S c$. arenicola were examined (Fig. $3 \mathrm{k}$ and 1). Limbs are absent, as is the pectoral girdle. In one specimen a vertical ilium is present on both sides, and the left ilium appears to be shifted caudally by approximately one vertebral length. It is difficult to tell whether any other pelvic bones are present. In the other specimen the pelvic girdle is present on both sides and includes ilia that lean caudally, each about the diameter of a rib. On each side the ischium appears as a pointed, transversely oriented sliver, widely separated from its counterpart. The pubes extend craniomedially and nearly meet in the midline at $c$. 1.5 VLA. The pelvic girdles are not connected to the vertebral column. A tiny femur, less than the length of one vertebra, is present on the right side. In a previously figured specimen of this species the pelvic girdle on each side retains all three bones, and at least one rudimentary femur is present (Renous \& Gasc, 1979, Fig. 3).

For all the examined African skink specimens, the limbs and girdles are functionally insignificant for locomotion. The limbs are too miniscule to serve as organs of propulsion, and the girdles are unconnected to the vertebral column and are too reduced to support a full limb and the muscles that operate it for propulsion (with the exception of the pelvic girdle of $S e$. bayonii). In each case if a limb is present its distal end is partly or fully missing. These structures therefore satisfy the criteria listed in the Introduction for identification as vestigial structures. 


\section{Discussion}

Although our study is limited to a few species of lizards, its results are interesting when viewed in the larger context of evolutionary phenomena associated with vestigiality. Three such phenomena of importance are intraspecific variation in vestigial structures, bilateral asymmetry in vestigial structures within individuals, and the sequence in which skeletal structures are lost within a lineage.

As Darwin (1871) noted, vestigial structures are prone to much intraspecific variation. Within our sample this phenomenon is exemplified by variation in the reduction of the pelvic girdle and limb in $S c$. arenicola. One of the examined specimens has ilia, ischia, pubes and femurs, while the other has ilia alone. In addition, for three of the skink species examined here, our specimen differs from at least one described individual of the same species. Our specimen of A. meleagris lacks a bony pectoral girdle, whereas a previously described specimen has one (Fürbringer, 1870). The femur alone is present in our specimen of L. stylis but is accompanied by a tibia and fibula in three previously examined specimens (Greer, 1987). Our specimen of $L$. carpentariae lacks hindlimbs altogether, whereas previously described specimens retain vestigial hindlimbs; some of the latter retain a single digit and others lack hindlimb segments distal to the tarsus (Greer, 1983). Previously authors have noted intraspecific variation in the vestigial appendicular skeletons of skinks (e.g. Essex, 1927; Greer, 1983). Intraspecific variation is also present in vestigial structures of other taxa. For example, the degree of reduction in the vestigial hindlimbs varies within each of several species of whale (Bejder \& Hall, 2002). Among humans the coccyx - a vestigial tail - varies in curvature, amount of fusion and number of segments (Postacchini \& Massobrio, 1983). The chimpanzee coccyx also varies in amount of fusion, number of segments and shape of the terminal segment (P. Senter pers. obs.).

It is also noteworthy that some variation occurs between the two sides of a single animal. For example, in our sample the pectoral girdle is present only on the right side in our specimens of L. carpentariae and Sc. anguina, and the ilium (without the ischium and pubis) is present only on the left side in the specimen of $A$. meleagris. To our knowledge, bilateral asymmetry in the presence/absence of a bone has not previously been documented in skinks. We also observed asymmetry as to the location of the pelvic girdle between the two sides of the animal in Sc. anguina, Sc. arenicola, and the adult $S e$. bayonii. It is noteworthy that in our sample bilateral asymmetry in the presence/absence of a given bone or in the placement of a girdle occurs only in cases of extreme reduction. It has also been recorded previously in a case of extreme reduction: a specimen of $S c$. arenicola in which the pelvic girdle on one side is shifted caudally three vertebral lengths with respect to the pelvic girdle on the other side (Renous \& Gasc, 1979, Fig. 3). Bilateral asymmetry in vestigial skeletal structures is limited neither to Squamata nor to the appendicular skeleton. For example, in chimpanzees, the left and right transverse processes of the first vertebra of the coccyx may differ in whether or not they meet and/or co-ossify with their counterparts on the last sacral vertebra (P. Senter pers. obs.).

An important implication of the intraspecific variation in vestigial limbs in skinks is that degree of limb reduction cannot necessarily be used to diagnose species in reducedlimbed members of Scincidae. The researcher is therefore cautioned to place greater emphasis on scalation and other characters for species identification.

In vestigial structures, both intraspecific variation and left-right asymmetry underscore the uselessness of these structures. If selective pressure to maintain a biological structure in its unreduced, symmetrical form is relaxed enough to allow the degree of variation in reduction and asymmetry noted here, then symmetry and a lack of reduction in the structure are obviously of no importance to the animal. This is to be expected in a structure, that is, itself, of no importance to the animal. The fact that a bone that is present in some individuals is absent in others of the same species, demonstrates that in that species, the bone is of no importance.

Interestingly, vestigial girdles resemble each other across Squamata (Essex, 1927; Stokely, 1947; Bellairs, 1950; Mlynarski \& Madej, 1961; Stephenson, 1961; List, 1966; Kearney, 2002). In most cases the pubis and ischium are much more strongly reduced than the ilium, which is usually the longest bone if all three are present in vestigial form. These trends are borne out in the skink sample presented here. Also, in our sample and across Squamata, if only one pelvic bone remains it tends to be the ilium. This suggests that the genes and/or developmental processes that govern limb and girdle loss are similar across Squamata. An exception is the burrowing snake genus Typhlops, in which the ilium and pubis tend to be lost before the ischium (Essex, 1927; List, 1966). Evidently, in Typhlops some change has taken place in the genes and/or developmental processes that govern limb and girdle loss.

\section{Acknowledgments}

We would like to thank Addison Wynn and Kenneth Tighe of the United States National Museum, for access to and help with specimens and equipment. J.G.M. would also like to thank his friends Aaron and Ta'Shanah McLean for lodging and transportation during the trip. We also thank Michael Caldwell and an anonymous reviewer for helpful suggestions that improved this manuscript. J.G.M.'s portion of this project was undertaken as part of an undergraduate Special Problems course in Biology at Fayetteville State University.

\section{References}

Bejder, L. \& Hall, B.K. (2002). Limbs in whales and limblessness in other vertebrates: mechanisms of evolutionary and 
developmental transformation and loss. Evol. Dev. 4, 445-458.

Bellairs, A.d.'A. (1950). The limbs of snakes, with special reference to the hindlimb rudiments of Trachyboa boulengeri. Br. J. Herpetol. 4, 73-83.

Branch, B. (1998). Field guide to the snakes and other reptiles of southern Africa. San Sanibel: Ralph Curtis.

Campbell, N.A., Reece, J.B., Taylor, M.R., Simon, E.J. \& Dickey, J.L. (2009). Biology. Concepts and connections, 6th edn. San Francisco: Pearson Benjamin Cummings.

Cope, E.D. (1892). The osteology of the Lacertilia. Proc. Am. Phil. Soc. 30, 185-221.

Darwin, C. (1871). The origin of species and the descent of man in relation to sex. London: John Murray.

Essex, R. (1927). Studies in reptilian degeneration. Proc. Zool. Soc. Lond. 4, 879-945.

Fürbringer, M. (1870). Die Knochen und Muskeln der Extremitaten bei den Schlangenähnlichen Sauriern. Leipzig: Verlag von Wilhelm von Engelmann.

Greer, A.E. (1983). A new species of Lerista from Groote Eylandt and the Sir Edward Pellew Group in northern Australia. J. Herpetol. 17, 48-53.

Greer, A.E. (1987). Limb reduction in the lizard genus Lerista. 1. Variation in the number of phalanges and presacral vertebrae. J. Herpetol. 21, 267-276.

Greer, A.E. (1991). Limb reduction in squamates: identification of the lineages and discussion of the trends. J. Herpetol. 25, 166-173.

Isaak, M. (2007). The counter-creationism handbook. Berkeley: University of California Press.

Kardong, K.V. (2006). Vertebrates. Comparative anatomy, function, evolution. Boston: McGraw Hill.

Kearney, M. (2002). Appendicular skeleton in amphisbaenians (Reptilia:Squamata). Copeia 2002, 719-738.

List, J.C. (1966). Comparative osteology of the snake families Typhlopidae and Leptotyphlopidae. Ill. Biol. Monogr. 36, $1-112$.

Mlynarski, M. \& Madej, Z. (1961). The rudimentary limbs in Anillidae (Serpentes). Br. J. Herpetol. 3, 1-6.

Palci, A. \& Caldwell, M.W. (2007). Vestigial forelimbs and axial elongation in a 95 million-year-old non-snake squamate. J. Vertebr. Paleontol. 27, 1-7.

Postacchini, F. \& Massobrio, M. (1983). Idiopathic coccygodynia. Analysis of fifty-one operative cases and a radio- graphic study of the normal coccyx. J. Bone Joint Surg. $\mathbf{6 5}$, 1116-1124.

Renous, S. \& Gasc, J.P. (1979). Etude des modalities de reduction des membres chez un Squamate serpentiforme: Scelotes, scincidé afro-malgache (1). Ann. Sci. Nat. Zool. Paris 1, 99-132.

Senter, P. (2010). Vestigial skeletal structures in dinosaurs. J. Zool. (Lond.) 280, 60-71.

Shapiro, M.D., Hanken, J. \& Rosenthal, N. (2003). Developmental basis of evolutionary digit loss in the lizard genus Hemiergis J. Exp. Zool. (Mol. Dev. Evol.) 297B, 48-56.

Skinner, A., Lee, M.S.Y. \& Hutchinson, M.N. (2008). Rapid and repeated limb loss in a clade of scincid lizards. $B M C$ Evol. Biol 8, Online DOI: 10.1186/1471-2148-8-310.

Smythe, R.H. (1967). The horse: structure and movement. London: J. A. Allen and Company.

Starr, C. \& Taggart, R. (2004). Biology. The unity and diversity of life, 10th edn. Belmont: Thomson Brooks Cole.

Steiner, H. \& Anders, G. (1946). Zur Frage der Entstehung von Rudimenten. Die Reduktion der Gliedmassen von Chalcides tridactylus. Rev. Suisse Zool. 53, 537-546.

Stephenson, N.G. (1961). The comparative morphology of the head skeleton, girdles and hind limbs in the Pygopodidae. J. Linn. Soc. Zool. 44, 627-644.

Stokely, P.S. (1947). Limblessness and correlated changes in the girdles of a comparative morphological series of lizards. Am. Nat. 38, 725-754.

Whiting, A.S., Bauer, A.M. \& Sites, S.W. Jr (2003). Phylogenetic relationships and limb loss in sub-Saharan African scincine lizards (Squamata:Scincidae). Mol. Phylogenet. Evol. 29, 582-598.

Wiens, J.J., Brandley, M.C. \& Reeder, T.W. (2006). Why does a trait evolve multiple times within a clade? Evolution $\mathbf{6 0}$, 123-141.

Witmer, L.M. (1995). The extant phylogenetic bracket and the importance of reconstructing soft tissues in fossils. In Functional morphology in vertebrate paleontology: 19-33. Thomason, J. (Ed.) Cambridge: Cambridge University Press.

Young, R.L, Caputo, V., Giovannotti, M., Kohlsdorf, T., Vargas, A.O., May, G.E. \& Wagner, G.P. (2009). Evolution of digit identity in the three-toed Italian skink Chalcides chalcides: a new case of digit identity frame shift. Evol. Dev. 11, 647-658. 